\title{
COMPREHENSIVE APPROACH: THE BULGARIAN DEFENCE EXPERIENCE IN CRISIS MANAGEMENT AND DISASTER RELIEF
}

\author{
Avgustina TZVETKOVA
}

\begin{abstract}
Opening remarks by the Deputy Minister of Defence of Republic of Bulgaria at the Second Workshop on Multinational Cooperation in Civil-Military Interoperability in Sofia, underlining the role multinational approaches and advanced technologies can play to increase the efficiency in the process of developing crisis management and disaster relief capabilities. The paper lists current Bulgarian initiatives, including the creation and hosting of a NATO Centre of Excellence in Crisis Management and Disaster Relief.
\end{abstract}

Keywords: Defence reform, crisis response operations, capability development, multinational cooperation.

Dear participants,

It is my great pleasure to welcome all of you to Bulgaria, in the National Defence Academy and in the Second Workshop Multinational Civil-Military Interoperability, co-hosted by NATO C3 Agency and the Bulgarian MOD.

The modern security environment contains a broad and evolving set of challenges to the security of NATO and Nations. Acting alone, it is impossible to meet successfully many of them. The effective implementation of NATO comprehensive approach requires an enhanced cooperation and contribution of all major actors, including the United Nations, the European Union, Governmental and Non-Governmental Organizations. In order to assure needed security, the NATO Lisbon Summit Declaration and the Strategic Concept entrust the Alliance with three essential core tasks: Collective Defence, Crisis Management and Cooperative Security. Their execution requires that NATO and Nations find a proper way to respond and to enhance needed common capabilities for better civil-military interaction.

Following the efforts of NATO and Nations to meet the new security challenges through Smart Defence and comprehensive approaches, as well with appropriate de- 
fence capabilities, the Bulgarian Ministry of Defence continuously works to enhance the national defence system as well as to broaden Bulgarian contribution to the collective defence and the security in the Euro-Atlantic area. Only for the last years we provided our national security system and armed forces with a number of basic strategic documents - National Security Strategy, Force Structure Review, National Defence Strategy, White Paper on Defence and the Armed Forces, Armed Forces' Development Plan. Pursuing their implementation, we are initiating a number of important projects, aimed to improve the management of defence and the armed forces. The basic task for us was to build a strategic environment for conducting the reforms, to introduce building integrity in defence with its pillars: transparency, accountability and fight against corruption.

One of the projects, based on the Bulgarian experience in South-Eastern European cooperation and Regional and NATO Crisis Management operations and exercises resulted in the initiative to assume responsibility for establishment of a NATO Crisis Management and Disaster Relief Centre of Excellence (COE). The establishment of such a COE reflects Bulgarian security policy to support NATO and Nations capability building process. The previous week we concluded an energy security driven exercise that brought together participants from eight countries from our region. The exercise "Energy Flame 2011" was the first exercise aimed to resolve a regional energy security crisis on the territory of the Balkan countries. We exercised regional collaboration and interoperability, as well as participation of a broad spectrum of governmental and non-governmental organizations.

We also support the NC3A initiative and the agency efforts to improve civil-military cooperation and coordination by providing comprehensive solutions to Nations. NC3A has an extensive experience in supporting NATO and Nations' efforts in the application of Crisis Response Measures and conducting Crisis Response Operations. By co-hosting this workshop, we follow our common goal to establish a collaborative civil-military domain, where the most critical problems are identified and analyzed, and solutions are explored, specified and validated.

These workshops are directed to find proper ways to leverage common interests and national activities and to provide forums to communicate and inform a subject matter Community of Interest, in order to enable the visibility and exchange of information between civil and military bodies, nodes and systems. We are planning for these two days to discuss the status of Multinational Cooperation in Civil Military Interoperability Initiative, to have a look at the NC3A packages from the stakeholders' perspective, to introduce to you the Bulgarian experience of building capabilities in support of crisis management and disaster relief, and to seek new ways ahead for future collaboration. 
I think this busy schedule will provide us with a common understanding of the need for a closer multinational cooperation in civil military interoperability, as well as with new ideas to broaden it in the future.

Welcome again, and I wish you a very successful work.

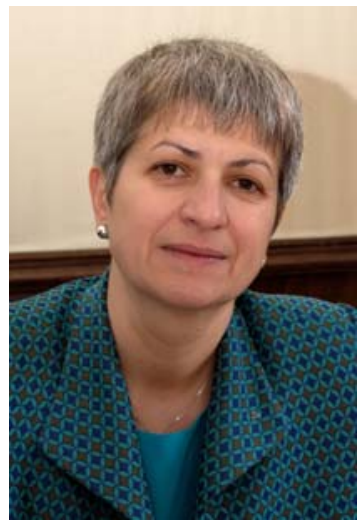

AVGUSTINA TZVETKOVA is a deputy minister of defence of Bulgaria since the spring of 2010 with responsibilities in international, legislative, information, social, property management, counter corruption and other policies of the MOD. She is a graduate of "St. Kliment Ohridski" Sofia University with a major in history and archaeology. After a professional career as a journalist, she became Programme Director and Secretary General of the Atlantic Club of Bulgaria (1995 - 2006), Vice President and Secretary General of the Atlantic Association of Young Political Leaders (1997-2001) and Vice President of the Atlantic Treaty Association in Brussels (2004-2007). From 2004 to 2009 she was President of the Euro-Atlantic Education Initiative Foundation, and from 2009 to 2010 - political advisor to Nickolay Mladenov

in his capacities as both Minister of Defence and later Foreign Affairs Minister. Avgustina Tzvetkova has specialized in the International Language Academy, Oxford, the George C. Marshall European Center for Security Studies and the US State Department. She is a member of the Advisory Board of the International Institute for Political and Economic Studies (IIPES). Her areas of specialization encompass foreign policy, relations with NATO and the USA and anti-corruption policies, as well as regional and Euro-Atlantic integration. E-mail: atzvetkova@mod.bg 